\section{Comment}

In our study less than $2 \%$ of the variance in blood pressure was explained by changes in the urinary excretion of sodium. Nevertheless, the finding that a raised blood pressure was associated with the combination of a fast pulse rate and a high urinary excretion of sodium is compatible with the suggestion of Poulter $e t$ al that a high sympathetic tone is a prerequisite for sodium to act as a pressor substance.' Alternatively, a high intake of sodium may facilitate the pressor effect of sympathetic stimulation. In our study smoking and consumption of alcohol were ruled out as confounding factors, but no information was available on the subjects' psychological stress and usual physical activity and therefore a possible influence of these two factors cannot be excluded.

Subjects with a slow pulse rate might have a low sympathetic tone; if their intake of sodium increases from 50 to $300 \mathrm{mmol} / 24 \mathrm{~h}$ sympathetic tone might be inhibited further and the secretion of renin suppressed, resulting in a fall in blood pressure. In contrast, people with a fast pulse rate might have an enhanced sympathetic tone and less effective baroreflexes; if their intake of sodium increases above $160 \mathrm{mmol} / 24 \mathrm{~h}$ the high sympathetic tone might prevent the inhibition of renin secretion and impair the ability of the kidney to excrete sodium, ${ }^{+}$thus causing the blood pressure to rise. Increasing the intake of sodium may therefore have opposite effects depending on the prevailing sympathetic tone.

1 Poulter NR, Shiplev MJ, Bulpitt CJ, Markowe HJ, Marmot MG. Pulse rate and twenty-four hour urinary sodium content interact to determine blood pressure levels of male London civil servants. 7 Hypertens 1998;6 (supp $4: 611-3$

2 Staessen J, Bulpitt CJ, Fagard R, Joossens JV, Lijnen P, Amery A. Salt intake and blod pressure in the general population: a controlled intervention trial in two towns. F Hypertens 1988;6:965-73.

3 Floras JS, Sleight P. The lability of blood pressure. In: Amery A, Fagard R, Lijnen P, Staessen J, eds. Hypertensive cardiovascular disease: pathophysiolog and treatment. The Hague: Martinus Nijhof, 1982:104-17.

4 Light KC. Koepke JP, Obrist PA, Willis PWIV. Psychological stress induce sedium and fluid retention in men at high risk for hypertension. Science $1983: 220: 429-31$.

(Accepted 15 Seplember 1989)

\title{
Quality of life of elderly people after surgery for benign oesophageal stricture
}

\section{B N M Jayawardhana, K Moghissi, J Knox}

\section{Department of Medicine for the Elderly, Kingston General Hospital, Hull B N M Jayawardhana, MRCP, registrar \\ J Knox, FRCP, consultant physician \\ Cardiothoracic Unit, Castle Hill Hospital, Cottingham, \\ Hull \\ K Moghissi, FRCs, consultant surgeon}

Correspondence to: Dr Jayawardhana, Department Barnet General Hospital,

High Barnet, Herts

EN5 3DJ.

Br.Med f 1989:299:1503-4 of Medicine for the Elderly,

Benign oesophageal stricture in elderly patients is usually treated by intermittent dilatation and drug treatment to control continuing symptoms of reflux. ${ }^{2}$ But this treatment has complications. ${ }^{3}$ We assessed the results of surgery for stricture in elderly patients by using a validated quality of life scale ${ }^{+}$in patients in whom endoscopic dilatation was unsuccessful or impossible because of the severity of the stricture.

\section{Patients, methods, and results}

We assessed consecutive operations performed between 1971 and 1983 for histologically confirmed benign oesophageal stricture in 124 patients (85 women, 27 men) aged 70 and over (range 70-89, mean $76 ; 16$ patients were over 80 ). Sixty eight patients were alive, 44 had died, and 12 were excluded from the study because hospital records were untraceable for nine and death records unavailable for three. Surgery was performed by $\mathrm{KM}$ and the survivors assessed independently by BNMJ.

Twenty four patients had medical disorders that

State of health of 68 survivors of surgery for oesophageal stricture according to Fanshel and Bush index

\begin{tabular}{|c|c|c|c|c|}
\hline Quality of life index & Asymptomatic & $\begin{array}{l}\text { Reflux } \\
\text { only }\end{array}$ & $\begin{array}{l}\text { Dysphagia } \\
\text { only }^{\star}\end{array}$ & $\begin{array}{l}\text { Reflux and } \\
\text { dysphagia* }\end{array}$ \\
\hline $\mathrm{S}_{\mathrm{A}}$ : wellbeing & 21 & 3 & $2(26)$ & $1(1)$ \\
\hline $\begin{array}{l}\mathrm{S}_{\mathrm{B}} \text { : dissatisfaction (group that includes most of the } \\
\text { population) } \\
\mathrm{S}_{\mathrm{C}} \text { : discomfort (minor symptoms that do not }\end{array}$ & 5 & 2 & $1(8)$ & 0 \\
\hline appreciably alter efficiency) & 2 & 4 & $0(5)$ & $0(1)$ \\
\hline $\mathrm{S}_{\mathrm{D}}$ : minor disability (reduced efficiency) & 8 & 1 & $3(16)$ & 4 \\
\hline $\mathrm{S}_{\mathrm{E}}$ : major disability (severe reduction in expected & 1 & 0 & $1(2)$ & 0 \\
\hline $\begin{array}{l}\mathrm{S}_{\mathrm{r}} \text { : disabled but ambulatory (yet able to contribute to } \\
\text { society) }\end{array}$ & 1 & 0 & 0 & 0 \\
\hline $\begin{array}{l}\mathrm{S}_{\mathrm{G}}: \text { confined to home } \\
\mathrm{S}_{\mathrm{H}}: \text { confined and bedridden }\end{array}$ & 5 & 1 & $1(4)$ & $0(3)$ \\
\hline $\begin{array}{l}\mathrm{S}_{\mathrm{I}} \text { : isolated and in institution } \\
\mathrm{S}_{\mathrm{J}}: \text { coma } \\
\mathrm{S}_{\mathrm{K}}: \text { death }\end{array}$ & 0 & 0 & $1(1)$ & 0 \\
\hline Total No $(\%)$ & $43(63)$ & $11(16)$ & $9(13)$ & $5(7)$ \\
\hline
\end{tabular}

${ }^{\star}$ No of patients with symptoms before operation in parentheses. were likely to influence the outcome of surgery. Six had a previous history of carcinoma. Forty five had had a laparotomy and 13 repairs of hiatus hernia and gastro-oesophageal reflux. Seventeen were taking nonsteroidal anti-inflammatory drugs.

Intraoperative guided dilatation and an antireflux procedure were performed in 79 patients transthoracically. Thirty two required resection of the stricture because it was difficult to carry out the dilatation, or because of deep penetrating ulcer, or because of scarring with considerable oesophageal shortening. A Celestin tube was inserted in one patient when a malignancy was suspected.

Twelve patients died after operation (five from cardiac causes and two from pneumonia); seven had had conservative surgery and five had had resections (not significant $0.5>\mathrm{p}>0.1$ ); only one had had previous surgery on the oesophagus. Four further patients were too frail to return home and died in hospital. Twenty eight others died two months to 10 years (mean 42.5 months) after surgery. Five year mortality was $32 \%$.

The state of health of the 68 survivors was assessed from two to 14 years (mean 65.5 months) after surgery according to the index of Fanshel and Bush (table): 41 were in groups $S_{A}, S_{B}$, and $S_{C}, 13$ having occasional symptoms. Minor and major disabilities were caused by heart disease, arthritis, old age, or memory impair ment. The patient in group $S_{F}$ had had a myocardial infarction and was expected to return to group $S_{A}$. The patients in group $\mathrm{S}_{\mathrm{G}}$ were in wheelchairs because of arthritis. The one patient in an institution had dementia. Eight patients continued to receive drugs that were likely to cause local inflammation.

Fifty four of the 68 patients had no dysphagia. Six showed no improvement from the preoperative grade. Only two required further intermittent dilatation. Fifty two had no symptoms of reflux, but six were taking antacids, cimetidine, metoclopramide, or anticholinergic drugs alone or in combination. There was no significant difference in the incidence of dysphagia $(\mathrm{p}<0.5)$ or symptoms of reflux $(\mathrm{p}<0.5)$ between the conservative and radical procedures. Two patients had symptoms of the gas bloat syndrome. None required further surgery.

\section{Comment}

Surgery relieved the symptoms of benign oesophageal stricture in 43 of the 68 patients whose 
symptoms continued after dilatation; 13 others had occasional symptoms only. Though health gradually deteriorates even if symptoms are controlled by dilatation and drugs, 41 patients had a satisfactory quality of life after surgery (groups $S_{A, B}$ and $C$ ).

There was no appreciable difference in either postoperative mortality or recurrence of symptoms in the two groups having conservative or radical surgery. The 30 day mortality was similar to that reported for younger patients ${ }^{35}$ and might be reduced with better selection of patients. The five year survival in our patients was $68 \%$. More elderly patients should be considered for surgery for oesophageal stricture.

1 Stoddard CJ, Simms JM. Dilatation of benign oesophageal strictures in the outpatient department. Br 7 Surg 1984;71:752-3.

2 Croker JR, Vallon AG, Cotton PB. Benign oesophageal stricture in the elderlyuse of cimetidine and fibre-optic dilatation. Age Ageing 1980;9:53-8.

3 Williamson RCN. The management of peptic oesophageal stricture. $B r f$ Sur $1975 ; 62: 448-54$

4 Fanshal S, Bush JW. A health-status index and its application to health-service outcomes. Operations Research 1970;18:1021-66.

Mohansingh MP. Mortality of oesophageal surgery in the elderly. Br f Surg 1976;63:579-80.

(Accepted 12 September 1989)

\section{Antral Helicobacter pylori, hypergastrinaemia, and duodenal ulcers: effect of eradicating tho organism}

\author{
Sassoon Levi, Kate Beardshall, Ian Swift, \\ William Foulkes, Ray Playford, Prodyot Ghosh, \\ John Calam
}

Department of Medicine,
Royal Postgraduate
Medical School, London
W12 ONN
Sassoon Levi, MRCP,
honorary registrar
Kate Beardshall, BSC,
research fellow
Ian Swift, FRCS, registrar
William Foulkes, MRCP,
registrar
Ray Playford, MRCP, registrar
Prodyot Ghosh, MRCP,
registrar
John Calam, FRCP, senior
lecturer

Correspondence to: Dr Calam.

Br Med f 1989;299:1504-5
There is strong epidemiological evidence to support a relation between colonisation of the gastric antrum with Helicobacter pylori (previously Campylobacter pylori) and duodenal ulcers,' though the basis of this association is speculative. We recently showed that in patients with duodenal ulcers secretion of gastric acid stimulated by pentagastrin and postprandial plasma gastrin concentrations are significantly higher in patients positive for $H$ pylori than in those negative for the organism..$^{2}$ In the present study we examined whether the high postprandial gastrin concentrations respond to treatment that eradicates $H$ pylori.

\section{Patients, methods, and results}

We studied 51 patients with active duodenal ulcers. Seven were negative for $H$ pylori and 44 positive on urease testing of antral biopsy specimens. ${ }^{2}$ Secretion of gastric acid was determined with pentagastrin $(6 \mu \mathrm{g} / \mathrm{kg} / \mathrm{h})$. Venous blood was collected before and after a standard meal for radioimmunoassay of gastrin.

Peak secretion of acid stimulated by pentagastrin was $45 \cdot 2$ (SEM 3.0$) \mathrm{mmol} / \mathrm{h}$ in the patients who were positive for $H$ pylori compared with $29 \cdot 7(4 \cdot 0) \mathrm{mmol} / \mathrm{h}$ in those who were negative $(p<0.05)$. Basal gastrin concentrations were significantly higher in the patients who were positive for $H$ pylori $(13 \cdot 1(2 \cdot 0)$ $v 6.3(2.6) \mathrm{pmol} / \mathrm{l}, \mathrm{p}<0.05)$. Integrated plasma gastrin responses to the standard meal were 1564 (267) pmol.min/l in the patients positive for $H$ pylori and 965 (248) pmol.min/l in those negative for $H$ pylor $(\mathrm{p}<0.05)$.

Ten of the patients positive for $H$ pylori were treated with metronidazole $400 \mathrm{mg}$ thrice daily for two weeks and colloidal bismuth subcitrate $120 \mathrm{mg}$ four times daily for four weeks. ${ }^{3}$ Two days after completing treatment nine patients were negative for the organism. Integrated postprandial gastrin responses fell from 1184 (350) to 498 (117) pmol.min/l $(\mathrm{p}=0.005)$ while peak rates of secretion of acid remained unchanged (figure). Basal gastrin concentrations, however, were not significantly lower after treatment $(7 \cdot 5(1.8) v 6.7$ (1.9) $\mathrm{pmol} / \mathrm{l}$, respectively).

\section{Comment}

We showed that eradicating antral $H$ pylori in patients with duodenal ulcers leads to a significant drop in the postprandial response of plasma gastrin concentration. This supports our contention that $H$ pylori is responsible for hypergastrinaemia in patients with duodenal ulcers. ${ }^{2}$

Patients with duodenal ulcer disease tend to have higher rates of secretion of gastric acid and higher postprandial plasma gastrin concentrations than controls. Walsh et al showed that a low intragastric $\mathrm{pH}$ inhibits release of gastrin less effectively in patients with duodenal ulcer disease than in normal subjects. ${ }^{4}$ On the basis of our recent results ${ }^{2}$ we proposed that $H$ pylori in the gastric antrum increases the release of gastrin. $H$ pylori produces a powerful urease that splits
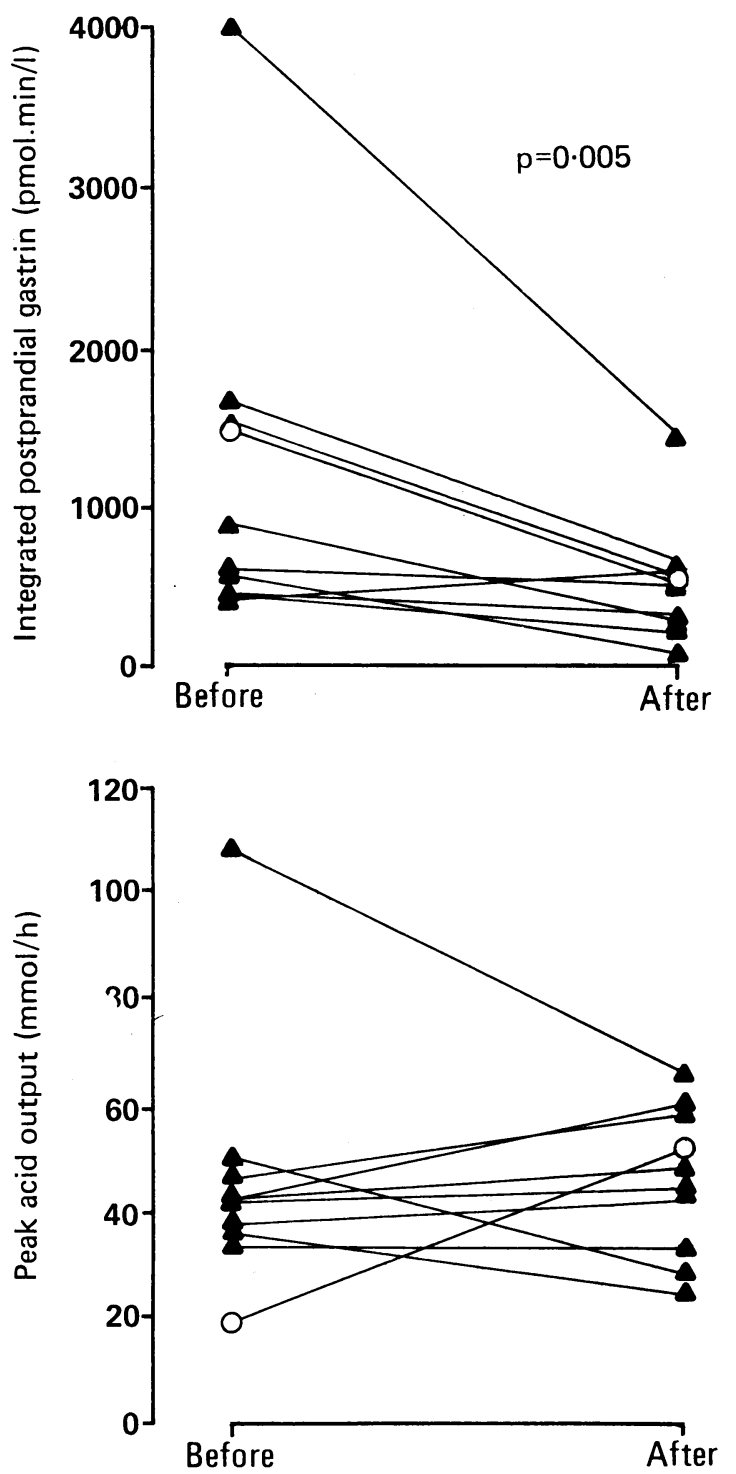

Changes in integrated postprandial gastrin responses and peak acid output in 10 patients before and after treatment with colloidal bismuth subcitrate for four weeks and metronidazole for two weeks. $\mathrm{O}-\mathrm{O}=$ Patient in whom urease test after treatment yielded weakly positive result 